by employing a full-time Emergency Management Coordinator-a pioneering position within Melbourne hospital systems. This role is broad, encompassing not only planning, but also the best practice research related to incident management, facilitation of site-based planning committees, promotion of linkages with local and state government bodies and other emergency service organizations, and the development and dissemination of educational and planning information to staff. This presentation outlines the development of this role, and provides an overview of current progress and challenges.

Providing services to an area of $1,335 \mathrm{~km}^{2}$, with a population of 553,000 people in Melbourne's western suburbs, Western Health employs 3,800 staff members by combining the resources of three leading hospitals and two specialized health programs: (1) an Aged Care and Rehabilitation Program (two nursing homes); and (2) a Drug and Alcohol Program. All hospitals are located within 20 minutes from Melbourne's central business district, and are within a major industrial petro-chemical producing belt for the State of Victoria, incorporating several major transport routes and an international and domestic airport.

Keywords: Australia; emergency medical coordinator; health; Melbourne; Western Health

Prebosp Disast Med 2005;20(2):s98-s99

\section{Road Traffic Injuries in Shanghai}

Z.M. Liu

Shanghai East Hospital, China

Worldwide, road traffic injury has become the primary public safety hazard. According to the World Health Organization (WHO), the total number of motor vehicles in the world is $>1$ billion, with $>80 \%$ in the developed countries and $<20 \%$ in the developing countries. In 2000 , an estimated 1.26 million people worldwide died as a result of road traffic injuries. The WHO predicts that road traffic injuries will account for about 2.3 million deaths globally per year by 2020 .

In 1978, the Chinese government began an open reform policy. Since then, the national economy has developed rapidly. In 2002, the number of motor vehicles in China totaled $79,756,763$. The average increase in the total motor vehicle production is $3.5 \%$ globally, and $26.4 \%$ in China for the same period. Meanwhile, however, road traffic incidents have increased at relative rates. In 2003, at the time of writing, road traffic incidents totaled 667,507 in China. This resulted in 494,174 injured patients and 104,372 deaths.

The population in Shanghai, at present, is nearly 20 million. There are 1.5 million motor vehicles within the city and the number has increased yearly. The density of population and vehicles is the highest of all Chinese cities. Although there are more and more subways and highways and roads are being widened, road traffic injuries have increased yearly. Statistics show there were 47,088 and 54,197 road traffic incidents in 2002 and 2003, respectively; there were 1,400 and 1,406 resulting deaths and 15,690 and 15,752 injured persons, respectively. Traffic injuries cost 30.05 and 39.72 million Yuan in each of those two years, respectively.
The emergency medical response in Shanghai involves the Shanghai Emergency Medical Service system and Emergency Medical Centers. The mean radius of the prehospital medical emergency network is about 15 kilometers. The "1-2-0" telephone system and other emergency numbers, such as the "1-1-0" police telephone number and the "1-1-9" fire telephone number activate the first-aid service system, which provides immediate feedback, and avoids spending time on unnecessary prehospital procedures. These emergency phone numbers have played an important role in emergency medical care in Shanghai.

In 1998, Shanghai East Hospital established a modern trauma care system and a Trauma and Emergency Center. In the Trauma and Emergency Center, there are various experienced specialists working in general surgery, neurosurgery, thoracic-cardiac surgery, orthopedic surgery, urological surgery, and professional enhanced intensive care units (EICUs) under the auspices of a coordinated emergency system. This system has performed successfully and should become the model in the management of road traffic injury patients, especially for patients with multiple injuries and for mass casualties.

Keywords: China; crashes; enhanced intensive care unit; emergency; injuries; public health; road; Shanghai; traffic; World Health Organization

Prebosp Disast Med 2005;20(2):s99

\section{Rapid Intervention Teams: The Mexican Experience in Prehospital Attention with Emergency Medical Technicians on Motorcycles}

S. San Martin Faur; G.Z. Sierra

Mexico

Introduction: In Mexico, increasing population and the corresponding increases in emergency response distances and need for emergency medical services have forced Mexican agencies involved in the delivery of emergency medical services to develop new and creative solutions to achieve their goals.

Methods: The Fire Department of Atizapan County (in the suburbs of Mexico City) implemented a Motorcycle Emergency Medical Technician's Team consisting of a Rapid Intervention Team with emergency medical technicians (EMTs) on motorcycles, as a complement to the already existing teams on ambulances. When an emergency call is received, an EMT on a motorcycle is dispatched immediately to the scene. The EMT arrives at the scene before the ambulance, and in that time starts the treatment of the victim with the equipment carried on board, stabilizes the patient, and provides early medical care (in the "Golden Hour"). At the beginning of the project, none of the EMTs had previous experience with this kind of team, so it was necessary to define the necessary job requirements of the participating EMTs, the proper medical and safety equipment, and the medical training and driving skills required in emergency conditions.

Results: Implementation of the Motorcycle Medical Technician's Team dramatically has reduced the arrival time of the medical care team to the scene and contributed to diminishing the morbidity and mortality of the victims. 
The arrival time of the first Motorcycle EMT to the scene is within 1-10 minutes, was, previously, with the regular ambulance service, the arrival time was between 5-60 minutes. Also, the first EMT on the scene now is able to determine if the ambulance really is necessary, avoiding spending valuable resources on patients who don't require ambulance services.

Conclusion: While the development of this project has taken considerable time and discussion (including safety and political issues), its implementation has allowed the Local Fire Department to increase the reach of their medical team and also decrease the cost of their operations.

Keywords: emergency medical technicians; emergency medical services; Mexico; motorcycles; response; time

Prebosp Disast Med 2005;20(2):s99-s100

Epidemiology of Burns in Edo State, Nigeria: The Need for Appropriate Documentation and Policy Interventions

E. Okparavero

Ghana, Africa

The complications and sequelae associated with burn injuries are one of the most devastating forms of traumatically induced injuries. The objective of this study was to define the vacuum created by the lack of appropriate and complete data during disasters. This is essential for establishing the importance trauma as a public health problem, and therefore, requires acquiring accurate data concerning its incidence and outcomes. Such documentation is essential in order to move towards shaping policies that will forestall the recurrence of certain incidents and the prevent future disasters.

The ability to document that the incidence of traumainduced injuries is reaching epidemic proportions in developing countries like Nigeria depends heavily on the use of healthcare records obtained primarily from records of hospital admissions and emergency department visits. Currently, these data only are of limited value since many of them are incomplete, and thus provide an imperfect picture of the overall situation. This has a serious effect, since without this documentation, appropriate personnel, facilities, and money will not be made available to deal with emergency or disaster situations.

Keywords: data; documentation; incidence; Nigeria; records; resources; trauma-induced injuries

Prebosp Disast Med 2005;20(2):s100
Playing Nicely in the Sandbox: The Monumental Task of Multi-Agency Coordination in Preparing for the United States Presidential Inauguration in the Nation's Capital

C. Catlett

The George Washington University Center for Emergency Preparedness, Washington, DC USA

Washington, DC has its share of challenges when it comes to the complexities of federal and local cooperation during major emergencies and events. Due to its high-profile nature, preparations began in the fall of 2004 for the 20 January 2005 inauguration of President Bush, the first inaugural event since 11 September 2001. In addition to conventional disasters (fires, transportation crashes, etc.), disruptive demonstrations and terrorist attacks are contingencies for which plans were made. The nation's capital launched a massive, multi-jurisdictional, multi-agency effort to coordinate its preparedness and response for the weeklong activities. A veritable alphabet soup of federal, state, and local response agencies met regularly to gain an understanding of respective functions and hash out issues of resource sharing, command and control, coordination, communications, security, and transportation. The presentation will focus on the coordination of medical response between local agencies, such as hospitals, the DC Department of Health, and DC Fire and Emergency Medical Services, and federal agencies/assets such as the United States Armed Forces and the National Disaster Medical System. A summary of the medical care provided during the week-long event will be presented.

Keywords: coordination; multi-agency; preparedness; response; terrorism; Washington, DC

Prebosp Disast Med 2005;20(2):s100

Need for a Nationwide Coordination Model for Disasters Involving Large Numbers of Burns and Current Status of Turkish Burn Care Facilities

M. Haberal; O. Basaran; A. Kut; E. Sakallioglu; G. Moray Baskent University Faculty of Medicine, Turkey

Burn injuries are one of the most common types of injuries during or following a disaster. In regards to natural disasters, Turkey is considered one of the most threatening places on earth. Since the beginning of the 20th Century, there have been 90 earthquakes, leading to a combined total of 82,359 deaths and 567,297 damaged buildings in Turkey. Between 1988 and 2001, there were 443,119 firerelated events, which led to 2,569 deaths, resulting from burns alone. According to data from March 2003, there are 218 beds in 23 specialized burn units nationwide and an additional 76 burn care beds reserved in hospitals that do not contain burn units $(0.44 / 100,000$ beds). Although burn units and hospitals with dedicated burn beds are widely distributed across the country, the cooperation between these burn units and hospitals and the healthcare system in Turkey needs to be coordinated, especially in disaster situations. 